\title{
Transition from master craftsman to engineering degree
}

DOI: $10.46932 / \operatorname{sfjdv2n2-012~}$

Received in: january 1st, 2020

Accepted in: March 30th, 2020

\author{
Clément Imbert \\ Faculty of Engineering, The University of the West Indies, Trinidad, West Indies \\ E-mail: clementimbert40@gmail.com \\ Reynold John \\ MIC Institute of Technology, Trincity Business Park, Macoya, Trinidad \\ E-mail: rjohn@mic.co.tt
}

\begin{abstract}
There is a great need for Master-Craftsmen who are highly valued in industry locally but are not afforded the same recognition as in Germany, so in order to encourage more applicants a bridging progression to a Bachelor's degree should be devised. There are several paths to the education of engineers. Traditionally students of engineering attend secondary school from which they matriculate to a tertiary institution. In many countries candidates may opt to do an Associate degree articulating to a Bachelor's degree. However, in some countries, it is possible to become an engineer without a traditional degree, usually in a more practically-oriented apprenticeship programme. In Britain for example, such candidates complete National Vocational Qualifications (NVQs) in engineering while working at a company. NVQs typically range from Level 1 to Level 8, Levels 6 and 7 being equivalent to Bachelor's and taught Master's degrees respectively. In Germany, there is also an alternative qualification to the Bachelor's degree, the more practically-oriented Meister (Master-Craftsman in English), both of which are equally recognized and respected professionally and are both pegged at Level 6 in the 8-Level German National Qualifications Framework (NQF). The MIC Institute of Technology has adopted a Master-Craftsman programme which is accredited by the German Chamber of Crafts and Trades. Candidates have to first complete the (trimester) Journeyman programme comprising three years, about $50 \%$ of which comprise industrial attachments/internships. Successful Journeyman graduates can progress to the Master-Craftsman qualification by completing an extra (trimester) year of study. This paper deals with the progression of Master-Craftsman graduates, through advanced placement, in a Bachelor of Technology programme. The Master-Craftsman curricula have to be mapped against a typical Bachelor of Technology programme to determine the gaps in mathematical, theoretical and other areas and mechanisms to fill any gaps.
\end{abstract}

Keywords: Bachelor's Degree, Master Craftsman, Transition

\section{INTRODUCTION}

The Meister is the highest professional qualification in technical vocational education and training (TVET) in Germany and is a state-approved qualification administered by the 53 Chambers of Crafts and Trades in (cities throughout) Germany which are also responsible for the recognition of foreign vocational training qualifications [1] by means of the Gesetz zur Ordnung des Handwerks, $\mathrm{HwO}$ (Crafts and Trades Regulation Code) [2]. The qualification is offered in a wide variety of disciplines and in Germany, only people with the Meister title are allowed to run certain businesses, especially the construction trades, but 
other areas as well. For example, one could not run a bakery without the presence of a Meister qualified in the field.

The education includes theoretical and practical training in the particular technical disciplines as well as business and pedagogical/andragogic training so as to enable the graduate to work as an instructor in a technical institution and/or train apprentices in the workplace.

The traditional English translation of Meister is Master-craftsman. However, given the level of education and training that the Meister undergoes, a more appropriate descriptor would be "Technologist" or at least "Advanced Diploma", in the context of the Advanced Diploma being granted after the completion of the discrete third year in a four-year programme (after GCSE/O Levels) in the British Qualifications Framework as shown in the following progression [3]:

- Certificate IV (after Year 1)

- Diploma NVQ 3/Higher National Certificate (after Year 2)

- Advanced Diploma NVQ 4/Higher National Diploma (after Year 3)

- Bachelor's Degree Equivalent (after Year 4)

However, in Germany in 2012 the "Meisterbrief" (the Meister certification) was declared equivalent to a Bachelor's degree in the sense that both are at Level 6 in the German Qualifications Framework for Lifelong Learning (Deutscher Qualifikationsrahmen für lebenslanges Lernen). However, it is not an academic degree as such and thus not directly comparable [4].

There are two stages to becoming a Master-Craftsman - one has to acquire the Journeyman (Geselle) qualification by successfully completing the examination (Gesellenprüfung) and apprenticeship, followed by the Meister education and training to prepare for the Meisterprüfung (Meister examination). The examination includes theoretical, practical and oral parts and may take up to a week (depending on the discipline). In some disciplines the creation of a masterpiece, for example workshop technology, is also part of the examination. Up until 2004 the regulations required practical working experience of 3 years as a Journeyman before one could study for the Meister examinations. Since then one can go straight into the Meister training upon graduation with the Journeyman certificate.

In 1994, the National Skills Development Programme (NSDP) was initialized in Trinidad and Tobago by the Metal Industries Company Ltd (MIC), now the MIC Institute of Technology (MIC-IT), as a Twinning Project in collaboration with the ICON-INSTITUT of Germany, to adapt the German Model of Technical Training to Trinidad and Tobago as a response to the need within the labour market for highly skilled and experienced technicians and technologists [5]. The ICON-INSTITUT is a German consulting firm involved in technical training, among other things. Organizations outside of Germany 
have to partner with an approved German company in order to officially adopt the Journeyman/MasterCraftsman programme and have it certified by one of the Chambers of Crafts and Trades.

The Programme follows the German Dual System of Technical Vocational Training and uses the Factory Training Concept where theoretical and practical skills are developed in the MIC Institute of Technology and practical mastery of these skills are developed in the industry under guided supervision of a skilled Supervisor or Master-Craftsman. The programme is accredited by the Chamber of Crafts and Trades in the city of Aachen, which sends an official of the Chamber to ensure that the local programme (at MIC Institute of Technology) is conducted according to German international criteria and that the curricula keep up with technological developments.

The Journeyman programme takes 3 Years full-time. In the $1^{\text {st }}$ Year Trainees are exposed to several occupational areas such as electrical technology, mechanical engineering technology including workshop technology, welding and industrial maintenance. In the $2^{\text {nd }}$ and $3^{\text {rd }}$ Years, trainees have to select one occupational area in which to specialize. The disciplines available at MIC-IT are:

- Electrical Engineering Technology

- Mechanical Engineering Technology

- Mechatronics

Trainees are placed in industry on attachment and return to classes at their respective training centres one day per week during the $2^{\text {nd }}$ year and two days per week during the $3^{\text {rd }}$ year.

The Master-Craftsman programme, which takes ten months, may be pursued after having successfully completed the Journeyman programme. MIC-IT has been able to have four months of the ten months conducted in Germany (including industrial training) [5].

\section{ADVANCED ADMISSION TO UNIVERSITY DEGREES}

Advanced admission to university degrees take place in many parts of the world, particularly in the United States where community colleges traditionally offer Associate Degrees which are very often directly articulated to university degrees where transferability of credits between institutions is common. Many students in the US decide to begin their course of study at a community college to earn an associate degree, and then continue on to a Bachelor's degree at a university. This allows students to save money, study closer to home, build up their academic confidence, take care of the general education requirements, and transition directly into their degree programme.

Because Associate degrees are typically two years in length, students will transfer into a Bachelor's degree programme with two years of general education and foundation-level courses completed, and only have to take courses directly related to their specialty. This means students who complete articulated 
associate degrees will only have to spend two additional scheduled years to complete their Bachelor's degree.

The Faculty of Engineering of The University of the West Indies used to grant advanced admission (into the $2^{\text {nd }}$ year of the 3-year Bachelor's degree) to graduates of the College of Arts, Science and Technology (CAST) of Jamaica, who had successfully completed the Diploma in Engineering. The Diploma was originally the UK Higher National Diploma (HND) which was subsequently localized. In September 1995 the college gained university status with the name University of Technology, Jamaica [6].

\section{DUAL BACHELOR/MEISTER PROGRAMME}

\subsection{THE EUROPEAN PROJECT}

"Key Action 2: Cooperation for Innovation and the Exchange of Good Practices" [7] is a project of the Erasmus + or Erasmus Plus programme. Erasmus Plus is the new programme combining all the EU's current schemes for education, training, youth and sport, which was started in January 2014. It is the current version of the Erasmus Programme (EuRopean Community Action Scheme for the Mobility of University Students), the European Union (EU) student exchange programme established in 1987 [8].

The Dual Bachelor/Meister [9] is part of "Key Action 2 ..." mentioned in the paragraph above and is coordinated in Germany by Hanse Parlament, Hamburg, on behalf of the Deutscher Akademischer Austauschdienst (German Academic Exchange Service). It started on September 1, 2017 and is expected to last until August 31, 2020. The aim of the project is the Development of a programme that combines the two qualifications: the academic Bachelor's and the vocational Master-Craftsman. The project report is expected to yield:

- Models and concepts for the integrated study courses;

- Modules' manuals for the study course for pilot programmes in construction, electrical engineering and real estate management;

- Examination regulations for Master-Craftsman and Bachelor's degree.

The project outcomes are expected to be:

i. An increase of relevance and quality as well as improve competencies and knowledge in both the vocational Master-Craftsman programme and the Bachelor's degree;

ii. Transfer of relevant professional skills and practical experience through the dual study approach;

iii. Important contributions to overcoming the shortage of entrepreneurs in SMEs;

iv. Bologna-compliant study, full international recognition; 
v. Contribution to the EU agenda for the modernization of Europe's higher education systems;

vi. Creation of permeability and reduce recognition problems;

vii. An increase in the attractiveness of vocational education and training.

\subsection{THE MIC-IT PROJECT IN TRINIDAD AND TOBAGO}

The MIC Institute of Technology has plans to embark on the implementation of a Dual Bachelor/Meister Programme along the lines of the European model as the outcomes of the European model are even more relevant to Trinidad and Tobago where the respect (and remuneration) in industry and academia of the Master-Craftsman is no way near that of the Meister in Germany and Europe in general.

A closer look at the above seven outcomes of the European project as they relate to the local context would be very instructive and bolster the case for its adoption in Trinidad and Tobago.

Outcome i: An increase of relevance and quality as well as improve competencies and knowledge in both the vocational Master-Craftsman programme and the Bachelor's degree.

Graduate engineers in the more industrialized countries are most often afforded the opportunity of structured training under the supervision of an experienced Engineer. This would occur in larger organizations or in programmes administered by professional bodies and/or the state which are often accessed by graduate engineers from smaller organizations. In the (industrially) developing countries such opportunities are not usually available to engineers in small to medium enterprises. In order to help fill this gap in some way, the MIC Institute of Technology conducts an Engineer-in-Training Programme whereby new graduates (trainee engineers) receive industrial training in a wide variety of manufacturing processes.

Outcome ii: Transfer of relevant professional skills and practical experience through the dual study approach.

Master-Craftsmen are highly skilled in the practical application of the various engineering technologies, whereas engineering graduates usually lack such practical skills but are more exposed to higher theoretical concepts, design and technological management principles, particularly those who pursue the classical Bachelor of Science degree rather than the Bachelor of Technology. The fusion of the two programmes, the very practical Master-Craftsman and more theoretical Bachelor's degree, would make for a more complete work-ready graduate who can hit the ground running rather than one who would likely experience ad-hoc unstructured industrial training which takes much longer to achieve the desired results and is often plagued with gaps.

Outcome iii: Important contributions to overcoming the shortage of entrepreneurs in SMEs. 
Entrepreneurs in technical endevours tend to be more successful if they have both the practical skills as well as a deeper understanding (theoretical knowledge) of their field and a greater appreciation of the principles of management. The dual trained engineer has a much greater chance of entrepreneurial success, in a shorter time (from graduation and start-up) than the person trained as either a MasterCraftsman or in a classical Bachelor's programme.

Outcome iv: Bologna-compliant study, full international recognition.

Outcome v: Contribution to the EU agenda for the modernization of Europe's higher education systems;

Outcome vi: Creation of permeability and reduce recognition problems;

The Bologna Accord [10,11] is the popular name for a declaration (Bologna Declaration) that was signed in June 1999 when 29 European countries agreed to reform higher education in Europe to achieve the following aims:

- Create a system of comparable and understandable degrees throughout the European Union

- Establish a clear and standard division between undergraduate and graduate studies

- Promote student mobility among different fields of study, institutions, and nations

- Develop a quality-assurance process and governing body to ensure standard qualifications and quality throughout participating countries

- Define a European focus for higher education

The agreement simplified degree qualifications and nomenclature and clarified the meaning of degrees by establishing a clear division between undergraduate and graduate studies by introducing uniform Bachelor's and Master's degrees to the education system in Europe to be more in line with the US, UK and the rest of the world.

Before the Accord, there was little uniformity in European higher education. Different countries' universities awarded different degrees, and it was not always clear which degree was equivalent to another. These distinctions made it difficult for graduate admissions offices and potential employers across borders to assess an applicant's level of education without researching degree qualifications, an onerous task, given the wide variety of diplomas even within a single European Union.

In continental Europe pre-Bologna, engineering degrees, for example, the Diplom-Ingenieur (Germany) and Diplôme d'Ingénieu (France) (roughly equivalent to a Bachelor's plus Master's degree) were scheduled to take 5 years to complete and often took longer. The length of these first degrees was a deterrent from attempting them and a barrier to graduation. Outside of Europe, the level of these degrees was not always understood. In addition to intra-European simplification, rationalization and standardization, Bachelor's and Master's degrees are more universally (internationally) recognized. By 
introducing the 3-year Bachelor's degree, Europe experienced many more graduates, more of whom went on to graduate school.

Matriculation for the 3-year Bachelor's degree in Germany is the Abitur examination taken at the end of secondary school and can be compared to $\underline{\text { A levels }}$ or the International Baccalaureate Diploma, which are all ranked at Level 4 in the European Qualifications Framework [12].

Outcome vii: An increase in the attractiveness of technical vocational education and training (TVET).

In many parts of the world, including the Commonwealth Caribbean, TVET has been differentiated from so-called academic streams of study and relegated in large measure to those who are considered unable to cope with the rigours of academic subjects. This has unfortunately led to the negative stigmatization of TVET and those who pursue this area of study. This attitude has spilled over to the profession of Engineering which had been considered inferior to the professions of Medicine and Law. This perception has experienced considerable change, no doubt due to the remarkable advances in, and dependence of, technology in the world today in all aspects of life including the professions.

This negative stigmatization (of TVET) has not been as acute in Europe where the MasterCraftsman qualification is at the same level as a Bachelor's degree (Level 6) in the Qualifications Framework for Lifelong Learning (Deutscher Qualifikationsrahmen für lebenslanges Lernen) in Germany [4], a technologically advanced country. Having said this however, the Master-Craftsman qualification by itself does not automatically qualify the holder to be admitted to a Master's degree programme.

The Dual Bachelor/Meister programme will provide a great incentive to those who are more practically inclined to enroll in a Master-Craftsman programme but who also wish to acquire the more universally recognized Bachelor's degree. In addition to the other very positive attributes outlined previously, it would also provide that bridge to higher level tertiary level study such as a Master's degree.

\section{MAPPING THE MASTER-CRAFTSMAN CURRICULUM TO THE ENGINEERING DEGREE}

It is imperative to map the comparisons between programmes to observe and cognize the similarities and differences and to implement how much needs to be acquired to facilitate cohesion of both programmes of a Dual Master-Craftsman/Bachelor's Degree which can develop well-rounded competent, ready-to-work engineers in society.

Programme Mapping can be defined as a matrix that juxtaposes and visually epitomizes the alignment between programme goals and their associated outcomes and the techniques through which those outcomes are delivered. Implementing this process of mapping in the Master-Craftsman and 
Engineering Degree Programme can help programme administrators better plan, direct, and coordinate a particular programme. Furthermore, examining programme-related information in the mapping process can also reveal gaps in a programme's curriculum, thus, increasing the likelihood that students will achieve programme-level outcomes. One major challenge of programme mapping is the costs and resources associated with implementing this approach on a larger scale as well as the training and support required for faculty and staff which can have a significant impact on quality and scalability.

During the Programme Mapping Exercise for the Master-Craftsman Electrical/Electronic Engineering Technology Programme and Electrical/Electronic Engineering Degrees the four main areas of concentration of an Electrical/Electronic Engineering Programme were considered, namely:

i. Communication

ii. Power Systems

iii. Electronics

iv. Computer Engineering

There are many sub-disciplines in the above main areas and many tertiary institutions offer a combination of the aforementioned options in their engineering programmes, as well as offer separate degrees in different areas of concentration and the sub-disciplines. Effective mapping therefore, requires collaboration between institutions and between institutions and industry.

Functional Maps should also be developed for each area of concentration and by extension, course specific content to generate appropriate course outcomes thereby ensuring duration and depth of course/programme. Gaps in programmes could also be discovered through this process.

The MIC Institute of Technology has started the exercise of mapping the Master-Craftsman curricula in Mechanical and Electrical/Electronic Engineering Technology against several "comparable" degree programmes. A cursory examination of the mapping so far has revealed that the major differences are in the level of mathematics and certain broader aspects of the training of an engineer including the socalled soft skills.

\section{NEW UK VOCATIONAL QUALIFICATIONS - T LEVELS}

In 2016, the British government announced the introduction of $\mathrm{T}$ Levels on a phased basis. The first three T-levels were mentioned in 2017 [13]. In October, 2019, it was announced that they will be taught in 50 colleges in England from September 2020 with the roll out of 25 by 2022 . The government describes the introduction of T Levels as the biggest overhaul of technical education in Britain, and is an 
effort to enhance Britain's industrial competitiveness, which is low compared to the world's leading industrialized countries [14].

These vocational technical qualifications will be at the same level (Level 3) as A levels in the British Qualifications Framework. All T Level programmes will include industrial internships of at least 315 hours - or about 45 days. The curricula were developed with inputs from leading industry professionals from major companies and is expected to bring Britain more in line in technical education with countries such as Germany [14].

It has not been all plain sailing for $\mathrm{T}$ Levels as there has been pushback from various quarters. A report of the National Foundation for Educational Research (NFER) has stated that T-levels could be "tarnished" in the minds of students and parents if universities are not willing to recognize them. Geoff Barton, General Secretary of the Association of School and College Leaders, said the report should be "ringing alarm bells" and that more clarity as many of the elite UK universities are yet to decide whether they will accept students with these qualifications [15].

\section{CONCLUSIONS}

The Master-Craftsman qualification in the engineering disciplines has been experiencing some challenges regarding its attractiveness, credibility, scientific and mathematical competencies as opposed to a Bachelor's Degree in Engineering. However, the Master-Craftsman Programme creates individuals with extensive practical knowledge, technological competence, professional experience and pedagogical competencies, which makes the transference of knowledge and merging of programmes viable, due to the fact that the Bachelor's Degree lacks a significant proportion of these specific competencies. Consolidation of both programmes encompasses all aspects of engineering which develop a holistic individual in all necessary competencies. The combination would play a critical role in the advancement and development of the practice of engineering.

Skillful mapping of both programmes would allow the Master-Craftsman advanced admission in a Bachelor of Engineering programme to complete the programme in fewer years. Over one hundred (100) Master-Craftsmen can be so "elevated" in their specific engineering discipline in Trinidad and Tobago.

Although Master-Craftsmen are readily absorbed in industry, it is very important to grant them the opportunity to continue advancing their qualifications and professional status. Moreover, this acquisition should undoubtedly bring "parity of esteem" between Technical Vocational Education and Training (TVET) and so-called Academics - a much needed boost to lift the image of TEVT in Trinidad and Tobago and incentivize more persons to enter the Master-Craftsman programmes. 
The dual qualification system is particularly important for Trinidad and Tobago, where, as in many other countries, TVET is not accorded the respect (and remuneration) that such hands-on training and qualifications require in order to advance the economic development of the country in all areas of technology including the manufacturing sector which needs a large boost to fulfil its potential to make a much larger contribution to the nation's GDP. It is interesting to note that this sentiment also obtains in Britain, ironically the country that spawned the industrial revolution, with the introduction of the T Levels, vocational qualifications on par with the traditional A Levels. UK universities may have to develop a Bachelor of Technology degree as many other countries have done in addition to the existing traditional, classical Bachelor of Science in Engineering.

In several European countries students are streamed after the early years in secondary schools, so that more academically-oriented students tend to continue to research-oriented universities to pursue the classical Bachelor of Science Engineering degree while the more practically-oriented ones tend to choose the universities of applied science to pursue the Bachelor of Engineering or Bachelor of Technology degree, depending on the nomenclature used. In Germany the more research-oriented universities are referred to as RTWH (Rheinisch-Westfälische Technische Hochschule) while the so-called applied universities are referred to as FH (Fachhochschule). This does not mean that the FH universities don't do research and in fact many innovations are developed at these institutions. The Dual Bachelor/Meister concept refers to the Bachelor of Engineering/Bachelor of Technology degree awarded by the FH universities. 


\section{REFERENCES}

1. https://www.anerkennung-in-utschland.de/html/en/german_confederation_of_skilled_crafts.php

2. https://en.wikipedia.org/wiki/Trade_and_crafts_code_of_Germany

3. https://en.wikipedia.org/wiki/National_Vocational_Qualification

4. "Der Deutsche Qualifikationsrahmen für Lebenslanges Lernen". bmbf.de. (German Federal Ministry of Education and Research Bulletin, 16 May 2013

5. www.mic.co.tt

6. https://www.utech.edu.jm/about-utech

7. www.bachelor-meister.eu/

8. http://ec.europa.eu/education/erasmus/history_en.htm

9. www.bachelor-meister.eu/

10. https://en.wikipedia.org/wiki/Bologna_Process

11. "The Bologna Accord: A European Revolution with Global Implications", The Newsletter of the Graduate Management Admission Council, January-February, 2005. Main Office: PO Box 2969 Reston, VA20195, USA

12. https://en.wikipedia.org/wiki/Abitur

13. "Education Secretary announces first new T Levels", Department for Education, October 11, 2017

14. “Guidance - Introduction of T Levels”, Department for Education, UK, October 7, 2019

15. "Pupils who take government's technical qualification could miss out on top universities, experts warn". Article in the Independent by Eleanor Busby Education Correspondent December 10, 2019

16. The above Websites were accessed on January 10, 2020, except for No. 12 which was accessed on January 30, 2020. 